\title{
EFFICACY OF RETAILER REBATES AND DELAYED INCENTIVES UNDER CUSTOMER HETEROGENEITY
}

\author{
Asif Muzaffar ${ }^{1}$, Muhammad Nasir Malik $^{2, *}$ and Shiming Deng ${ }^{3}$
}

\begin{abstract}
In automobile and household appliances, the manufacturer's decision to offer retailer rebates to retailers or delayed incentives directly to end customers is very important. Under game theoretic environment, we show that delayed incentive is an important tool not only for price discrimination but it also provides more flexibility to the manufacturer. We differentiate the impact of delayed incentives and retailer rebates. We draw implications for optimal rebate strategies for both retailer rebates and delayed incentives. We also discuss delayed incentives in the form coupons that give more control to the manufacturer, whereas retailer rebates require retailer's participation. Analysis and numerical insights show that the manufacturer prefers better observance of retail price. We provide a decision rule to the manufacturer on how to select the rebate type based on customer heterogeneity.
\end{abstract}

Mathematics Subject Classification. 91B24.

Received August 5, 2020. Accepted April 24, 2021.

\section{INTRODUCTION}

In recent years delayed incentives, in the form of mail-in rebates, electronic rebates, automotive rebates are becoming very popular because of their general applicability for different situations. Moreover, retailer rebates (RR) or instant rebates have their importance as well. Proctor and Gamble were the first to issue rebates in the form of coupons to the end users in 1970s; since then many of the manufacturers and retailers have followed the same trend. The popularity of rebates is especially high in hi-tech industries, fashion apparels and computers. Rebates are an important instrument to stimulate the sales of products, especially the consumer-packaged products. Over $20 \%$ of the sales of products occur under sales promotions [37]. Interestingly, some empirical studies show that only $16 \%$ of the sales promotions are profitable [35]. From managerial perspective, there can be various motives for promotions, for instance, increasing market share and strategic consideration. Furthermore, there may be adverse effects in using promotions [24]. Adverse effect may arise for the manufacturer or the retailer and there is a need of a rebate strategy that defines the best rebate for the supply chain (SC) partners. This important issue is duly addressed in this research.

Keywords. Marketing-operations interface, delayed incentives, pricing and rebate strategies, heterogeneous customers and Stackelberg game.

1 University of Technology and Applied Sciences, Sur, Sultanate of Oman.

2 Institute of Business and Management, University of Engineering and Technology, Lahore, Pakistan.

3 Department of Operations Research and Logistics Management, School of Management, Huazhong University of Science and Technology, Wuhan, P.R. China.

*Corresponding author: nasir.malik@uet.edu.pk 
This paper investigates the impact of delayed incentives and retailer rebates. Rebates in the form of retailer rebates and delayed rebates are primarily used although the impact is quite different for both. Without loss of generality, we use term delayed rebates (DR) to represent mail-in rebates, electronic rebates and rebates that require certain effort to redeem after purchase. Delayed rebates show after purchase impact as they are not instantly redeemed, whereas retailer rebates have instant redemption. Manufacturers need to decide their rebate strategy for different market conditions. Usually retailer rebates and delayed rebates are the two plausible options to consider but manufacturers may prefer one type of rebate under certain market conditions. Conventionally, the economic literature has considered both rebates in a bilateral monopoly, subside to the same profit, quantities and prices [3]. An empirical study by Busse et al. [11] provided evidences from the automotive industry that such analogy does not always hold. The main advantage of delayed rebates is that only few customers will be redeeming it as shown through survey data by Soman [34]. Grow [22] reported that in the USA alone, rebate programmes worth US $\$ 6$ billion were offered every year and over $40 \%$ of all rebates were never redeemed. In 2005 , NPD through a survey of rebate redemption found that the most common reasons of customers' dissatisfaction were the preference of instant rebate $(35 \%)$, too much redemption effort $(25 \%)$ and forgot to redeem the rebate $(17 \%)^{1}$. These evidences show that delayed rebates are widely used but recently, manufacturers are using them sparingly because of adverse effects. Meanwhile, instant or retailer rebates are becoming very attractive in supply chains.

This paper investigates not only the impact of delayed rebates and retailer rebates but also compares them for a given rebate amount. We use analytical model to capture the characteristics of both rebates and for delayed rebate, our modeling base is from Khouja et al. [26], who suggested that delayed rebate is a profitable option in a single player setting as it not only price-discriminates, but also allows customers to self-select the segment based on their reservation price. They used explicit heterogeneity to find optimal price setting with delayed rebate. In contrast, we provide rebate policies in a game theoretic environment. The basis for our analytical model for delayed rebates is the inconsistent behavior of the customers in redeeming rebates.

In operations management perspective, inconsistent behavior was first analyzed by Chen et al. [15] who showed that DR is better for manufacturer when some customers do not redeem it. In contrast our model inculcates sequential game setting with one-shot inventory decision like Chen et al. [15]. We pose following research question based on these literatures:

(1) How does the impact of retailer rebates differ from delayed rebates in a two-level supply chain?

Demirag et al. [19] showed that retailer incentives perform better than consumer rebates, however, under stochastic environment, consumer rebates perform better than retailer incentives. In automotive industry, home appliances and electronic product manufacturers, there is no explicit analogy that proves one rebate type to be better than the other one. Our objective is to provide a decision rule that deals with the contradiction between conventional analogy and the current market practices in different industries. Based on these evidences, we pose our second research question:

(2) Should the manufacturer prefers one type of rebate to another?

We assume deterministic demand model because of better analytical traceability as suggested by Corbett and Karmarkar [17]. We presented a two-stage sequential game for both rebate policies and characterized the optimal solution. Delayed rebates work with customers bifurcated as rebate independent, partially and fully rebate dependent. Partially rebate dependents customers are inconsistent in redeeming rebate after sales, whereas fully rebate dependent customers duly redeem it.

Our contributions to the existing literature are as follows: We discuss two scenarios for comparison and optimality of both rebates. We first consider a rigid business environment in which the retailer and the manufacturer do not change the retail price and the wholesale price after the manufacturer offers either RR or DR. This scenario is very common in reality, especially in automotive industry where retailers rarely change the listed price because manufacturers establish a long term contractual relationship. The second scenario represents a

\footnotetext{
$1_{\text {http: }} / /$ search.proquest. com/docview/209935578?accountid=14681.
} 
semi-rigid environment a flexible environment in which the retailer has more power than the first scenario. He can adjust the retail price in response to rebate. In addition, we also examine a special case of finding the best rebate type for a fixed rebate amount for both scenarios.

The paper is organized as follows. Section 2 contains a brief review of related literature. In Section 3, we formulate the model, and provide a benchmark case without rebates. In Sections 4 and 5 respectively, we study the optimal rebates for the cases without and with the retailer adjusting the retail price and discuss several managerial insights. In Section 6, we discuss the industrial practices related to both types of rebates and conclude our paper in Section 7.

\section{Literature REVIEW}

There is a plethora of literature that addresses issues related to rebates. One of such issues is the attractiveness of delayed rebates and retailer rebates based on the fact that the sensitivity to promotions and regular prices are same. Similarly, the price discriminating features of delayed rebates are considered equally effective as a price cut by retailer rebates. First, We enumerate some relevant literature that stresses on the effectiveness of sales promotions. In marketing mix, sales promotions are the most important ones. Nelsin [31] mentioned that nearly $75 \%$ of marketing budget is for sales promotion.

Most of the sales promotion literature describes three types of promotions as given by Blattberg and Neslin [6]; trade promotion from the manufacturer to the retailer, retailer promotions from the retailer to the customer, and customer promotions from the manufacturer to the end customers. Their research is focussed on empirical studies. Researchers mainly from the marketing discipline find that delayed rebates (customer promotion) present a great opportunity for firms to increase their profits as reported by Mouland [29], the main advantage being few customers redeeming it and also the future price expectation is not lowered.

Based on the relevancy of literature, we classify rebates under (1) general setting and (2) game theoretic framework. Firstly, we summarize the relevant literature under general pricing and rebate framework in Table 1.

Our modeling base for delayed rebates stems from Khouja et al. [26]. We bifurcate customers into three segments: rebate independent, fully rebate dependent and partially rebate dependent in a game theoretic environment in a two-level supply chain. Rebate independent customers are not affected by rebate, fully rebate dependent customers are influenced by rebate and duly redeem it after purchase whereas partially rebate dependent customers' purchasing decision is based on rebate but do not redeem it later.

Unlike the earlier work on rebates in marketing and economics, we do not model how individuals respond to rebate offers; instead we model the effect of rebates on segmented demand through rebate sensitivity. The explicit heterogeneity allows us to incorporate pricing decision for delayed rebate and compares it with retailer rebate for a given rebate value.

Secondly, there is extant literature on rebates under game theoretic environment and we summarize relevant literature stream in Table 2.

Work of Aydin and Porteus [4] is quite similar to ours in terms of defining the role of both rebates when wholesale price is exogenously fixed and rebate is a decision variable. They showed that even if all customers redeem rebate, consumer rebates are still better for the manufacturer. Our work emphasize on defining explicit customers' heterogeneity for delayed rebates and conditions under which one form of rebate outperforms the other.

Our work has some correlation with papers like by Demirag et al. [19] as we assumed deterministic demand as well, but for consumer rebate we assumed explicit heterogeneity among the customers and categorized them into three segments as mentioned by Soman [34]. Contrary to Demirag et al. [19], we found that for deterministic demand setting, DR could create win-win situation depending upon rebate sensitivity and customers' behavior about product nature. We assumed retailer rebate with fixed retail price and analyzed cases when the manufacturer was better off. On the other hand, Demirag et al. [19] assumed price discriminating retailer which is a typical scenario for automotive industry and may not necessarily be applicable to other businesses. Furthermore, their work is primarily on finding which rebate works well under both the deterministic and stochastic settings, 
TABLE 1. Relevant literature streams under general setting.

\begin{tabular}{|c|c|c|}
\hline Authors & Key focus & Key findings \\
\hline Silk [33] & Delayed incentives & $\begin{array}{l}\text { Slippage behavior which refers to the } \\
\text { proportion of customers who fail to } \\
\text { redeem rebate after purchase }\end{array}$ \\
\hline Gerstner and Hess [21] & $\begin{array}{l}\text { Channel issues for one manufacturer, } \\
\text { one retailer case }\end{array}$ & $\begin{array}{l}\text { Even when price is not discriminating } \\
\text { customers, rebates are profitable for the } \\
\text { manufacturer }\end{array}$ \\
\hline Blattberg and Neslin [6] & Coupons and delayed rebates & $\begin{array}{l}\text { Instant coupons are the most important } \\
\text { type of rebates as they are instantly } \\
\text { redeemed }\end{array}$ \\
\hline Buzzell et al. [12] & Retailer rebates & $\begin{array}{l}\text { Retailers do not always pass the total } \\
\text { benefit to the end customers }\end{array}$ \\
\hline Lal $[28]$ & Different types of rebates & $\begin{array}{l}\text { Effectiveness of different types of } \\
\text { rebates }\end{array}$ \\
\hline Gerstner and Hess [20] & $\begin{array}{l}\text { Considered two market segment with } \\
\text { having customers with high reserva- } \\
\text { tion price and high transaction cost } \\
\text { when they redeem rebates. They ana- } \\
\text { lyzed four different rebates like trade } \\
\text { deals, delayed rebates, retailer rebates } \\
\text { and a combination of delayed rebates } \\
\text { and retailer rebates }\end{array}$ & $\begin{array}{l}\text { Proved different conditions that help } \\
\text { retailer to offer rebate to both customer } \\
\text { segments }\end{array}$ \\
\hline Khouja et al. [26] & $\begin{array}{l}\text { Provided analytical model for retailer } \\
\text { based rebate }\end{array}$ & $\begin{array}{l}\text { Used survey date bifurcate customers } \\
\text { into three segments: rebate indepen- } \\
\text { dent, fully rebate dependent and par- } \\
\text { tially rebate dependent }\end{array}$ \\
\hline Saha [32] & $\begin{array}{l}\text { Discussed three types of rebates induced } \\
\text { contracts using direct rebates }\end{array}$ & $\begin{array}{l}\text { Provided certain conditions under } \\
\text { which supply chain coordination was } \\
\text { achieved }\end{array}$ \\
\hline Taylor [36] & $\begin{array}{l}\text { Supply chain coordination in two-level } \\
\text { supply chains }\end{array}$ & $\begin{array}{l}\text { Quantity flexibility contracts achieve } \\
\text { supply chain coordination when rebates } \\
\text { are offered above a certain threshold } \\
\text { level }\end{array}$ \\
\hline Tsao et al. [38] & $\begin{array}{l}\text { Developed two models for retailer sales } \\
\text { promotions and manufacturer trade } \\
\text { promotions under demand uncertainty }\end{array}$ & $\begin{array}{l}\text { Wholesale price is a key factor in deter- } \\
\text { mining manufacturer's profit }\end{array}$ \\
\hline
\end{tabular}

whereas we determine the efficacy of the rebates from the manufacturer's perspective and derive conditions when one type of rebate supersedes the other.

To the best of our knowledge, no research work yet has defined optimal strategy for the manufacturer which creates win-win situation and gives the manufacturer a clear insight for decision making regarding certain type of rebate to offer under given market potential. Such strategy for decisive rebate is a new avenue of research. We incorporate customer segments and rebate sensitivity for defining optimal pricing and rebate strategy for DR, which also drew little attention in literature.

\section{MODEL ENVIRONMENT}

We model a two-echelon supply chain having one manufacturer and one retailer. First, we define the common notations used for benchmark setting and traditional analytical models for RR and DR. These notations are fairly 
TABLE 2. Relevant literature streams under game theoretic environment.

\begin{tabular}{|c|c|c|}
\hline Authors & Key focus & Key findings \\
\hline Arcelus et al. [1] & $\begin{array}{l}\text { Considered different supply chain set- } \\
\text { tings such as (1) a manufacturer who } \\
\text { offers rebate to the retailer or to the end } \\
\text { customer; }(2) \text { a customer who is price- } \\
\text { dependent; (3) a newsboy type retailer }\end{array}$ & Optimal rebate and pricing strategies \\
\hline Chen et al. [15] & $\begin{array}{l}\text { Examined the impact of manufacturer } \\
\text { rebate on manufacturer's and retailer's } \\
\text { expected profits when the retailer needs } \\
\text { to determine the order quantity so as to } \\
\text { meet uncertain demand }\end{array}$ & $\begin{array}{l}\text { One shot inventory and pricing deci- } \\
\text { sions to satisfy price dependent uncer- } \\
\text { tain customer demand }\end{array}$ \\
\hline Aydin and Porteus [4] & $\begin{array}{l}\text { Analyzed retailer rebate and manu- } \\
\text { facturer rebate in a newsvendor type } \\
\text { setting }\end{array}$ & $\begin{array}{l}\text { Showed that retailer rebate performs } \\
\text { better for the whole supply chain and } \\
\text { delayed rebates may not always be a } \\
\text { profitable option }\end{array}$ \\
\hline Demirag et al. [19] & $\begin{array}{l}\text { Analyzed automotive retailer and man- } \\
\text { ufacturer rebate strategies in a sequen- } \\
\text { tial game setting }\end{array}$ & $\begin{array}{l}\text { Provided theoretical results and } \\
\text { insights for current automotive indus- } \\
\text { try practices }\end{array}$ \\
\hline Cho et al. [16] & $\begin{array}{l}\text { Investigated different pricing and rebate } \\
\text { strategies for a two-level supply chain } \\
\text { based on wholesale price, retail price } \\
\text { and rebate in a Stackelberg game }\end{array}$ & $\begin{array}{l}\text { Provided rebate strategies to the } \\
\text { retailer under different market condi- } \\
\text { tions like high or low wholesale price }\end{array}$ \\
\hline Guiomar et al. [23] & $\begin{array}{l}\text { Comparison between retailer rebates } \\
\text { and cash rebates }\end{array}$ & $\begin{array}{l}\text { Optimal rebate strategies in a two-level } \\
\text { supply chain }\end{array}$ \\
\hline
\end{tabular}

common and used extensively in operations management and marketing literature [4,19,23]. These standard notations are as follows:

\section{Common notations used in benchmark setting and traditional models for $\mathrm{RR}$ and DR}

$a>0$ is the maximum purchase potential.

$b>0$ is the price sensitivity.

$d>0$ is the rebate sensitivity.

$w$ is the wholesale price which retailer pays to the manufacturer.

$P$ is the retail price at which customers buy the product.

$R$ represents rebate amount (either RR or DR). The manufacturer may offer a DR or RR of size $R$.

$D$ is the buying quantity.

$c$ is the production cost of the manufacturer.

$\Pi_{R}$ represents the retailer's profit.

$\Pi_{M}$ denotes the manufacturer's profit.

$\bar{P}$ is the benchmark retail price.

$\bar{w}$ is the benchmark wholesale price.

$\overline{\Pi_{M}}$ is manufacturer's profit in benchmark setting.

$\overline{\Pi_{R}}$ is retailer's profit in benchmark setting.

$\Pi_{\text {total }}$ is the total supply chain profit.

$\gamma$ is the fraction of retailer rebate passed on to the end customers such that $\gamma \geq 0$.

Next, we define the specific notations used in our analytical models. These notations are specifically used to capture the explicit heterogeneity and difference of profits for different decision scenarios. 


\section{Specific notations used in our proposed models}

$\alpha_{1}$ shows the proportion of rebate independent customers.

$\alpha_{2}$ is the proportion of partially rebate dependent customers.

$\alpha_{3}$ represents the proportion of fully rebate dependent customers.

$\bar{\gamma}$ represents the maximum fraction of retailer rebate passed to end customers.

$\Delta \Pi_{R}$ is the percentage difference between retailer's profit under scenario 1 and retailer's profit under benchmark setting.

$\Delta \Pi_{M}$ is the percentage difference between manufacturer's profit under scenario 1 and manufacturer's profit under benchmark setting.

$\Delta \Pi_{\text {total }}$ is the percentage difference between supply chain total profit under scenario 1 and supply chain total profit under benchmark setting.

$R_{c}$ denotes the equilibrium rebate amount.

$\Pi_{M_{\mathrm{DR}}}$ denotes the manufacturer's profit for a given DR.

$\Pi_{M_{\mathrm{RR}}}$ denotes the manufacturer's profit for a given RR.

\section{Modeling assumptions and descriptions}

(1) We consider the buying quantity $D$ to be linear and deterministic in price $P$ and rebate $R$. If there is no rebate, demand form is $D(P)=a-b P$.

(2) Both rebates have different impact; RR is instant and DR is redeemable after exerting some effort [15, 26]. For DR, We classify customers into three classes according to their responses. DR is modeled with heterogeneous customers i.e. customers have different redeeming probabilities. We assume the behavior as rebate independent, partially rebate dependent and fully rebate dependent customers. $\alpha_{1}$ are the rebate independent customers as they never look for rebate and they purchase if their reservation price is higher than the regular price. $\alpha_{2}$ are the partially rebate dependent customers who purchase only if there is a rebate but afterwards, fail to redeem it. $\alpha_{3}$ are fully rebate dependent customers who see the rebate, purchase the product and then redeem it as well. This behavior of rebates allows customers to self select as price discrimination occurs after purchase.

It is important to mention that $\alpha_{1}, \alpha_{2}$ and $\alpha_{3}$ are estimates of customers usually derived from marketing surveys conducted by companies. For example, Dalton [18] cited a survey which showed that $50 \%$ of customers did not find rebates to be attractive (rebate independent customers) because of many reasons like the redemption process was too complicated or rebate was not worth the effort. Similarly, NCH promotional services estimated that $18.5 \%$ of consumers always used rebates (rebate dependent customers). Moreover, delayed rebates provide uncertain savings as well when some customers do not redeem the rebate (partially rebate dependent customers) and slippage occurs which can be as high as $40 \%$ [16].

However, it should be noted that estimation of these three type of customers may not be a plausible option from historical data especially to differentiate $\alpha_{1}$ and $\alpha_{2}$ type of customers. So, the conventional practice is to conduct surveys to estimate the proportion of customers in these three categories.

\section{Model formulation}

Retailer rebate is modeled by a linear demand function.

The retailer's profit function is as follows:

$$
\Pi_{R}=(P-w)(a-b P+\gamma R) .
$$

The manufacturer's profit function is given by following expression:

$$
\Pi_{M}=(w-c-R)(a-b P+\gamma R) .
$$

Retailer rebate moves from the manufacturer to the retailer, who decides the fraction of rebate to pass on to the end customers. So, retailer rebate is instant for the end customer and thus, retailer rebate fails to discriminate 
price, but this very weakness allows direct rebate more fine-tuned control over who gets to buy the product. Traditionally, DR does not allow such fine control.

Similarly, DR is modeled using customers' heterogeneity and the retailer's profit and the manufacturer's profits are as follows:

$$
\begin{gathered}
\Pi_{R}=\alpha_{1}(P-w)(a-b P)+\alpha_{2}(P-w)(a-b P+d R)+\alpha_{3}(P-w)(a-b P+d R) \\
\Pi_{M}=\alpha_{1}(w-c)(a-b P)+\left(\alpha_{2}+\alpha_{3}\right)(w-c)(a-b P+d R)-\alpha_{3} R(a-b P+d R) .
\end{gathered}
$$

Rebate sensitivity $d$ is an important factor in defining the impact of DR on overall profits. We assume that the manufacturer never wants to set rebate value which is below his margin $w-c$.

Furthermore, we define two cases for DR, i.e. when all the customers are redeemers and when some of them fail to redeem it. DR with $100 \%$ redemption is a typical scenario which is true either when the manufacturer offers instant coupons to all the customers or DR is redeemed instantly at the time of purchase. We also have big stream of literature and research on consumers' inconsistent behavior in redeeming manufacturer rebates. Soman [34] and Silk [33] provide us the justification that some customers fail to redeem rebates after purchase.

We analyze both types of rebates for following two scenarios:

(1) When wholesale and retail price are long-term fixed ones. The rationale behind long-term fixed wholesale price and retail price is that rebate promotions are temporary price mark downs and the retailer may not have an incentive to negotiate retail price for shorter period of time. This is a real world scenario where rebate promotions are typical tools of delayed incentive in the supply chain especially in the automotive industry where retailers rarely change the published retail price in response to rebate.

(2) When wholesale price is fixed. In hi-tech and home appliances industries, the manufacturer does not usually change the wholesale price in response to rebate. Electronics dealers quickly change the price in response to rebates without negotiating a new wholesale price [27]. Such practices pose an interesting case of analyzing pricing and rebate strategies when wholesale price is held constant.

The manufacturer and the retailer enter into a Stackelberg game. We solve the Stackelberg game with the retailer setting optimal price at the last stage while at the first stage, the manufacturer sets the optimal wholesale price and rebate sequentially. Both stages are solved using backward induction. For retailer rebate, at second stage the retailer decides the retail price and fraction of the rebate to be passed to the end customers simultaneously. At first stage, the manufacturer chooses the optimal wholesale price and the size of rebate. Stackelberg game for DR is the same with the exception that all the rebate goes to the end customers directly from the manufacturer. Mathematical expressions are validated through MATLAB and numerical simulations were performed using MATLAB as well.

\subsection{Benchmark setting}

We consider a typical scenario in a decentralized supply chain when there is no rebate. The manufacturer and the retailer follow a Stackelberg game, each maximizing one's own profit. The manufacturer is the leader and chooses the wholesale price. The retailer is the follower, who sets the retail price in response to the wholesale price. Both players are rational in their decision making. This is the "best" possible solutions for a decentralized supply chain without rebates and we call it the decentralized benchmark. The solution for this is well known in the literature. We briefly outline it here. Given $w$, the retailer maximizes her profit: $\Pi_{R}=(P-w)(a-b P)$. The retailer's optimal price is given by following expression:

$$
\bar{P}(w)=\frac{1}{2}\left(\frac{a}{b}+w\right) .
$$

The manufacturer maximizes his objective function based on the decision of the retailer: $\Pi_{M}=(w-c)(a-$ $b \bar{P}(w))$ The wholesale price is given by following expression: $\bar{w}=\frac{1}{2}\left(\frac{a}{b}+c\right)$. Substituting $\bar{w}$ back to $\bar{P}$, we obtain the retail price: $\bar{P}=\frac{(3 a+b c)}{4 b}$. 
Firstly, we provide the optimal rebate strategies for the two types of rebates. Secondly, we investigate special case of finding the best rebate type based on a given rebate amount. We demonstrate this special case for two market settings. This special case points out an important real world practice where many manufacturers fix a rebate amount and then find the better rebate option in terms of profits.

\section{Scenario 1: Fixed $w, P, \gamma$ And optimal $R$}

\section{Long term price arrangement}

In automotive industry, manufacturers and retailers rarely change the published price during the selling season and manufacturers offer rebate. When the manufacturer offers rebate, Chen et al. [14] proved that the retailer may or may not increase his selling price in contrast to Aydin and Porteus [4] and Arcelus et al. [2] who argued that the retailer always increases retail price. We provide the optimal strategies for RR and DR for the given scenario and then demonstrate the better rebate strategy for a given rebate amount.

\subsection{Optimal rebate strategy}

We now provide the structural properties of the optimal RR and the optimal DR with and without heterogeneity and show effects on the manufacturer's profit and overall impact.

(1) Optimal RR policy.

Decisions are as per the Stackelberg game. The sequence is as follows: for a fixed retail and wholesale price, the manufacturer sees the opportunity to offer rebate. The retailer negotiates the pass through fraction $\gamma$ and determines the quantity. Long term arrangement prevents the retailer to change the retail price in response to rebate.

The manufacturer's problem is

$$
\begin{array}{cl}
\max _{R} & \Pi_{M}(R)=(w-c-R)(a-b P+\gamma R) \\
\text { s.t. } & 0 \leq R \leq w-c .
\end{array}
$$

The objective function of the manufacturer is a submodular function in $(\gamma, R)$ and we check for the optimality. For the manufacturer's function we have:

$$
\begin{aligned}
\frac{\partial \Pi_{M}}{\partial \gamma} & =R(w-c-R) \\
\frac{\partial \Pi^{2}{ }_{M}}{\partial \gamma \partial R} & =-2 R \leq 0 \\
\frac{\partial \Pi_{M}}{\partial R} & =(a-b p-2 \gamma R) \\
\frac{\partial \Pi^{2}}{\partial R \partial \gamma} & =-2 R \leq 0 .
\end{aligned}
$$

It is easy to infer that the manufacturer's objective shows submodularity in $(\gamma, R)$ and hence, we have a decreasing difference in $(\gamma, R)$. For fixed pricing strategy, the optimal rebate suffices following lemma.

Lemma 4.1. For exogenous $w, P$ and $\gamma$, optimal rebate expression is as follows:

$$
R^{*}=\frac{1}{2}\left[(w-c)-\frac{(a-b P)}{\gamma}\right]
$$

and it always creates win-win situation provided $(w-c)>\frac{(a-b P)}{\gamma}$ and $\gamma \geq \bar{\gamma}$ are satisfied simultaneously, where $\bar{\gamma} \in[0,1])$ and $\bar{\gamma}$ is the maximum fraction of rebate passed to the end customers. 
TABLE 3. Improvement in profits for RR with different $\gamma$.

\begin{tabular}{llllllllll}
\hline \hline$\gamma$ & $w$ & $R$ & $P$ & $\Pi_{M}$ & $\Delta \Pi_{M}$ & $\Pi_{R}$ & $\Delta \Pi_{R}$ & $\Pi_{\text {total }}$ & $\Delta \Pi_{\text {total }}$ \\
\hline 0.4 & 60 & 0 & 80 & 1000 & $0 \%$ & 400 & $0 \%$ & 1400 & $0 \%$ \\
0.5 & 60 & 5.0 & 80 & 1012.5 & $1.25 \%$ & 506.25 & $26.56 \%$ & 1518.75 & $8.48 \%$ \\
0.6 & 60 & 8.33 & 80 & 1041.67 & $4.17 \%$ & 583.33 & $45.83 \%$ & 1625.0 & $16.07 \%$ \\
0.7 & 60 & 10.71 & 80 & 1080.36 & $8.04 \%$ & 638.39 & $59.60 \%$ & 1718.75 & $18.54 \%$ \\
0.8 & 60 & 12.50 & 80 & 1125.0 & $12.5 \%$ & 675.0 & $68.75 \%$ & 1800.0 & $28.57 \%$ \\
0.9 & 60 & 13.89 & 80 & 1173.61 & $17.36 \%$ & 695.14 & $73.78 \%$ & 1868.75 & $33.48 \%$ \\
1.0 & 60 & 15.0 & 80 & 1225 & $22.5 \%$ & 700 & $75.0 \%$ & 1925.0 & $37.5 \%$ \\
\hline 0.5 & 55 & 0 & 77.5 & 1012.5 & $0 \%$ & 506.25 & $0 \%$ & 1518.75 & $0 \%$ \\
0.6 & 55 & 3.75 & 77.5 & 1020.94 & $0.83 \%$ & 594.0 & $17.33 \%$ & 1614.94 & $6.33 \%$ \\
0.7 & 55 & 6.43 & 77.5 & 1041.43 & $2.86 \%$ & 659.57 & $30.28 \%$ & 1701.0 & $12.0 \%$ \\
0.8 & 55 & 8.44 & 77.5 & 1069.45 & $5.62 \%$ & 707.48 & $39.75 \%$ & 1776.94 & $16.87 \%$ \\
0.9 & 55 & 10.0 & 77.5 & 1102.5 & $8.89 \%$ & 740.25 & $46.22 \%$ & 1842.75 & $21.33 \%$ \\
1.0 & 55 & 11.25 & 77.5 & 1139.06 & $12.5 \%$ & 759.38 & $50.0 \%$ & 1898.44 & $25.0 \%$ \\
\hline 0.6 & 55 & 0 & 75 & 1000 & $0.32 \%$ & 625.0 & $0 \%$ & 1625.0 & $0 \%$ \\
0.7 & 55 & 2.14 & 75 & 1003.21 & $0.32 \%$ & 679.54 & $8.73 \%$ & 1682.75 & $3.55 \%$ \\
0.8 & 55 & 4.38 & 75 & 1015.31 & $1.53 \%$ & 737.44 & $17.99 \%$ & 1752.75 & $7.86 \%$ \\
0.9 & 55 & 6.11 & 75 & 1033.61 & $3.36 \%$ & 781.14 & $24.98 \%$ & 1814.75 & $11.68 \%$ \\
1.0 & 55 & 7.50 & 75 & 1056.25 & $5.63 \%$ & 812.50 & $30.0 \%$ & 1868.75 & $15.0 \%$ \\
\hline
\end{tabular}

Proof. We use the benchmark $\bar{w}$ and $\bar{P}$ to check the condition in Lemma 4.1. Note that $\frac{a-b P}{\gamma}$ is continuous and decreasing in $\gamma$. At $\gamma=0$, the condition is violated. We increase $\gamma$ to its maximum value, 1 . If we can show that the condition is satisfied at $\gamma=1$, we prove this lemma. The inequality at $\gamma=1$ is as follows:

$$
\begin{aligned}
& \bar{w}-c \geq \frac{a-b \bar{P}}{1} \Leftrightarrow \bar{w}-c \geq \frac{a}{2 b}-\frac{\bar{w}}{2} \\
& \Leftrightarrow \frac{3 \bar{w}}{2} \geq \frac{a}{2 b}+c \Leftrightarrow \frac{3}{4}\left(\frac{a}{b}+c\right) \geq\left(\frac{a}{2 b}+c\right) \Leftrightarrow \frac{a}{b}-c>0 .
\end{aligned}
$$

The last inequality holds because $a-b P \geq 0$ and $P \geq c$. We impose technical assumptions to avoid trivial cases and uniqueness of solution. RR is a profitable tool for the manufacturer under such setting. Optimal rebate depends upon exogenous $\gamma$ and we provide more insight in the numerical results.

We emphasize on a setting when $w$ and $P$ are fixed with optimal $R$ is being offered by the manufacturer. So, $P$ and $w$ are fixed and $\gamma$ is negotiated.

Numerical insight. We provide numerical illustration when $w$ and $P$ are set at the benchmark level. We assume $a=100, c=10$ and $b=d=1$ for numerical insights. Table 3 shows that threshold level for $\bar{\gamma}$ exists for every set of $P$ and $w$ above which win-win situation is always created. For $P=80$ and $w=60$ the benchmark status quo are $\overline{\Pi_{M}}=1000$ and $\overline{\Pi_{R}}=400$. For $P=77.5$ and $w=55$, the benchmark optimal are $\overline{\Pi_{M}}=1012.5$ and $\overline{\Pi_{R}}=506.25$. The benchmark levels are $\overline{\Pi_{M}}=1000$ and $\overline{\Pi_{R}}=625$ when $P=75$ and $w=55$. It is straightforward from Table 3 that both players and the whole SC gets benefitted when $\gamma \geq \bar{\gamma}$. However, there is more burden on $\bar{\gamma}$ when $w$ is below $\bar{w}$. Higher $\bar{\gamma}$ is required to create win-win situation.

It is interesting to note that even if all the customers redeem rebate, RR is not the same as DR unless DR has the same rebate sensitivity ( $R R$ is instant and is similar to a direct price cut, whereas DR still requires some effort and customers do not perceive rebate sensitivities similar).

We examine DR and its impact on players' profits when customers exhibit inconsistent behavior in redeeming rebates. Chen et al. [15] and Khouja et al. [26] provide rationale for customer heterogeneity. Our analytical models provide managerial insights for decision making under customer heterogeneity. 
(2) Optimal DR with $100 \%$ redemption.

We adopt a demand function that is linearly decreasing in price. The manufacturer's profit function is as follows:

$$
\max _{R} \Pi_{M}(R)=(w-c-R)(a-b P+d R)
$$

and the retailer maximizes $\Pi_{R}=(P-w)(a-b P+d R)$. The optimal solution is recorded in following lemma.

Lemma 4.2. Under the fixed price strategy, optimal rebate expression is given as follows:

$$
D R^{*}=\frac{1}{2}\left[(w-c)-\frac{(a-b P)}{d}\right]
$$

For any given wholesale and retail prices, if $R^{*}>0\left(\right.$ i.e. $\left.(w-c)>\frac{(a-b P)}{d}\right)$, win-win situation always exists.

We can easily infer that the manufacturer gets worse off with decreasing $d$. Nevertheless, if the manufacturer perceives considerable rebate sensitivity, DR is a profitable option even if all the customers redeem it [4]. Though it pertains to the specific setting we assume, DR against the common notion is profitable even with all redeemers. Interestingly, both rebates seem to be similar in structure but differ significantly in their impact on customer.

(3) Optimal DR with inconsistent customers.

In this case, we look at the inconsistent behavior of the customers to redeem rebate after purchase. We differentiate such customers as partially rebate dependent customers and use linear deterministic demand function to capture the inconsistent behavior. The objective function of retailer is as follows:

$$
\Pi_{R}=\alpha_{1}(P-w)(a-b P)+\alpha_{2}(P-w)(a-b P+d R)+\alpha_{3}(P-w)(a-b P+d R) .
$$

It is easy to infer that for any given $P$ and $w$, any positive $R>0$ will benefit the retailer and ensure him to participate.

Next we look at the manufacturer's problem. The manufacturer's objective function is given as follows:

$$
\begin{array}{cl}
\max _{R} \quad \Pi_{M}=\alpha_{1}(w-c)(a-b P)+\alpha_{2}(w-c)(a-b P+d R) \\
\\
\quad+\alpha_{3}(w-c-R)(a-b P+d R) \\
\text { s.t. } \quad 0 \leq R \leq w-c .
\end{array}
$$

The function is strictly concave in $R$ for $d>0$ because the second term is linear, the third term is strictly concave and the first term is constant resulting in a strictly concave function.

From first order condition (FOC), we can derive the optimal rebate which is given by following expression:

Lemma 4.3. If $d \geq \frac{\alpha_{3}(a-b P)}{\left(\alpha_{2}+\alpha_{3}\right)(w-c)}$,

$$
R^{*}=\min \left\{w-c, \frac{1}{2}\left[\frac{\alpha_{2}+\alpha_{3}}{\alpha_{3}}(w-c)-\frac{(a-b P)}{d}\right]\right\} .
$$

Otherwise, $R^{*}=0$.

Proof. See Appendix A. 


\subsection{Special case: Better rebate type}

The manufacturer actually targets the gains from a specific rebate amount and may not look at the best profits and thus he may look for the efficient rebate type. In real practice, the manufacturer faces the dilemma of offering specific rebate type especially for frequently purchased consumer products and there are chances of adverse selection [24]. We investigate an interesting case when the manufacturer wants to find a rebate type for some given rebate amount.

For RR, the retailer optimizes the following objective function:

$$
\Pi_{R}=(P-w)(a-b P+\gamma R) .
$$

$\gamma$ is the fraction of retailer rebate passed on to the end customers such that $\gamma>0$.

The manufacturer's profit function is given by following expression:

$$
\Pi_{M}=(w-c-R)(a-b P+\gamma R) .
$$

Similarly, for DR, the objective functions for the retailer and the manufacturer are as follows:

$$
\begin{aligned}
\Pi_{R} & =\alpha_{1}(P-w)(a-b P)+\alpha_{2}(P-w)(a-b P+d R)+\alpha_{3}(P-w)(a-b P+d R) \\
\Pi_{M} & =\alpha_{1}(w-c)(a-b P)+\left(\alpha_{2}+\alpha_{3}\right)(w-c)(a-b P+d R)-\alpha_{3} R(a-b P+d R) .
\end{aligned}
$$

First, we discuss a case where all customers redeem; either because of instant rebates or the manufacturer ensures the $100 \%$ redemption of DR.

(1) When all customers redeem.

We present an important result for this case.

Proposition 4.4. If there is all redeemers tendency and $\gamma>d ; R R$ is altogether better performing rebate. Manufacturer prefers $D R$ when $\gamma<d$ and the manufacturer is indifferent to both the rebates when $\gamma=d$.

Proof. See Appendix A.

It seems that both rebate structures are similar but $\gamma$ and $d$ impact is different on the customers. For instance, if all customers are redeemers and $\gamma=d$, the manufacturer prefers RR because $\gamma$ is a predetermined parameter whereas $d$ represents actual rebate sensitivity perceived by the customers. So, RR offers better control to the manufacturer than DR and he may prefer RR to DR when he perceives $\gamma=d$.

\section{The insight}

From implementation perspective, this result is very important. For frequently purchase consumer goods, manufacturers may not be able to clearly differentiate price and rebate sensitivity. So, the rationale would be to get better control on the market price rather than relying on the retailer to participate in the rebate program. Under such market condition, the manufacturer may opt for coupons which are instantly redeemed with the purchase. Therefore, if third-degree price discrimination is not plausible in the market, the manufacturer opts for coupons which provide more control to him.

In a nutshell, the manufacturer decides control over better price observability. Specifically, he has two options:

(1) to offer DR and designs the redemption process such that all customers redeem it. This option is plausible when the manufacturer finds third-degree price discrimination unattractive for customers, or

(2) to offer RR if he wants the retailer to participate in the rebate program. This option is plausible when the manufacturer finds the rebate sensitivity undistinguishable in a market. The manufacturer prefers RR only to make the retailer participate in the rebate program.

However, this may not be true when customers are heterogeneous. We examine this in detail later in the next section. 
(2) When some customers fail to redeem DR.

Theorem 4.5. If there is a tendency of customers' slippage, there always exists a threshold rebate $R_{c}$ between $R R$ and $D R$ above which $D R$ supersedes $R R$. Below such $R_{c}, R R$ always outperforms DR. $R_{c}$ represents the equilibrium rebate value.

To sketch the proof of this theorem, we compare RR and DR analytically. The objective functions for retailer and manufacturer are given as follows:

$$
\begin{aligned}
\Pi_{R} & =(w-c-R)(a-b P+d R) \\
\Pi_{M} & =\alpha_{1}(w-c)(a-b P)+\left(\alpha_{2}+\alpha_{3}\right)(w-c)(a-b P+d R)-\alpha_{3} R(a-b P+d R) .
\end{aligned}
$$

\section{Analytical solution indifferent rebate value}

$$
\begin{aligned}
\alpha_{1}(w-c)(a-b P)+\left(\alpha_{2}+\alpha_{3}\right)(w-c)(a-b P+d R)-\alpha_{3} R(a-b P+d R)=(w-c-R)(a-b P+\gamma R) & \\
& \quad-\left(\alpha_{2}+\alpha_{3}\right) d R(w-c)+\alpha_{3} d R^{2}+\alpha_{3} R(a-b P)-R(a-b P)-\gamma R^{2}+\gamma R(w-c)=0 \\
\beta_{2}= & 0 \\
\beta_{1}= & \alpha_{3}(a-b P)-(a-b P)+\gamma(w-c)-\left(\alpha_{2}+\alpha_{3}\right) d(w-c) \\
\beta_{0}= & -\gamma+\alpha_{3} d \\
R_{c}= & \frac{-\beta_{1} \pm \sqrt{\beta_{1}^{2}-4 \beta_{0} \beta_{2}}}{2 \beta_{0}} .
\end{aligned}
$$

Such threshold value strictly follows the inequality:

$$
\mathrm{RR} \leq R_{c} \leq \mathrm{DR}
$$

such that

$$
\Pi_{M_{\mathrm{RR}}} \leq \Pi_{M} \leq \Pi_{M_{\mathrm{DR}}} .
$$

We can see that if there is some slippage, $R_{c}$ always exists such that DR is better performing above that level and below that point, RR is better. These analytical findings are confirmed by means of numerical illustration.

Proposition 4.6. Unless all customers are redeemers, threshold $R_{c}$ always exists and varies according to the customer distribution. Such $R_{c}$ always follows $\mathrm{RR} \leq R_{c} \leq \mathrm{DR}$.

\section{Analysis and discussion}

For comparative analysis of DR and RR, we use $\alpha_{1}=0.2, \alpha_{2}=0.2$ and $\alpha_{3}=0.6, w=60, P=80$ and $\gamma=1$. Figure 1 clearly depicts the crossing or indifferent rebate point which is the same as we found analytically in this case is about 20. At this point both rebates are indifferent for the manufacturer. We find that such crossing point exists for every combination of customer distribution if $\alpha_{2}>0$. Interestingly, such $R_{c}$ always exists and though it varies according to the customer distribution, it strictly follows the condition i.e. $\mathrm{RR} \leq R_{c} \leq \mathrm{DR}$.

\section{Scenario 2: Fixed $w$ With optimal $P$ And $R$}

Similar to scenario 1, we first analyze the case of optimal rebates and then define rebates comparison case. 


\section{DR with heterogeneity Vs. RR}

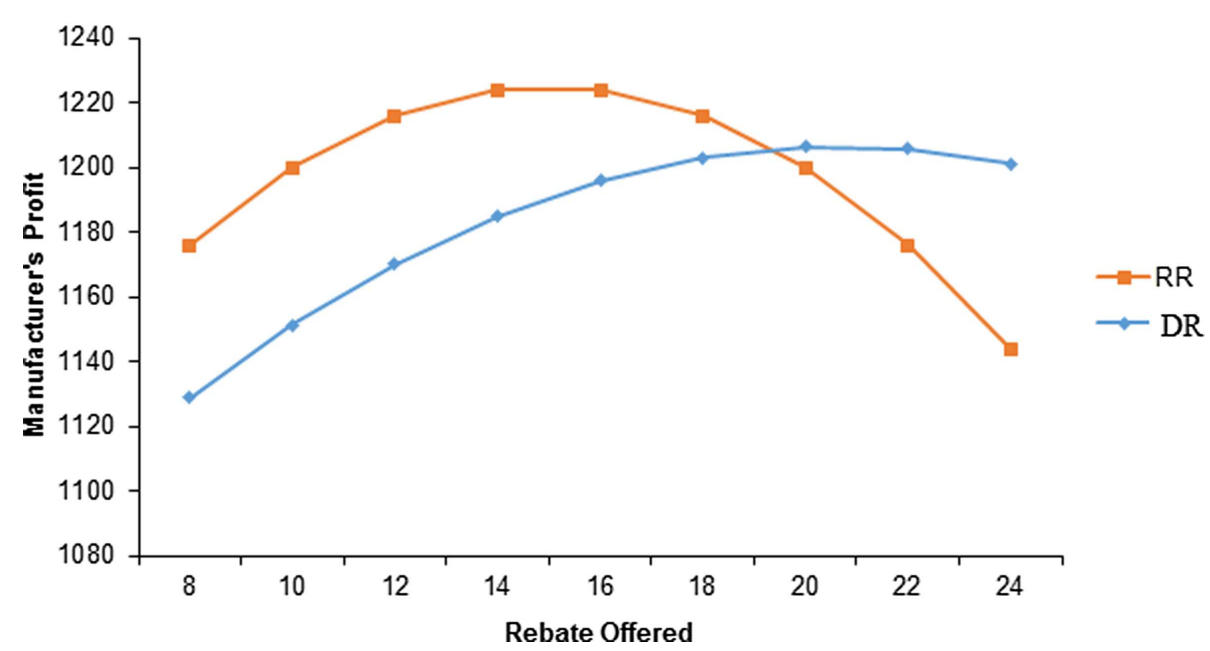

FiguRE 1. Crossing point between RR and DR (heterogeneous).

\subsection{Optimal policy for RR and DR}

\section{RR analysis}

We present the following lemma for this scenario:

Lemma 5.1. If $w$ is set above $\frac{1}{2}(a+c)$ for $R R$ with exogenous $w$, the manufacturer adjusts rebate such that his profit is maximized, i.e. he gets profit above the benchmark case. The retailer's optimization problem is given as follows:

$$
\max _{P} \Pi_{R}(P)=(P-w+R-\gamma R)(a-b P+\gamma R) .
$$

The optimal price is as follows:

$$
P^{*}=\frac{1}{2}(a+w-R+2 \gamma R)
$$

or apparent price is given by:

$$
P-\gamma R=\frac{1}{2}(a+w-R) .
$$

The manufacturer's corresponding optimization problem is given by following expression:

$$
\max _{R} \Pi_{M}(R)=(w-c-R)(a-b P+\gamma R)
$$

and optimal rebate for the manufacturer is as follows:

$$
R^{*}=w-\frac{1}{2}(a+c) .
$$

It is straightforward that effective price reduces by half of $R R$ offered. Interestingly, $\gamma$ does not have any impact on profit levels.

We draw two important implications here: 
(1) When $w$ is set higher than benchmark $\bar{w}$. The manufacturer and the whole supply chain is better off than the benchmark case. RR is attractive to the manufacturer and the whole supply chain as well.

(2) When $w$ is set at $\bar{w}$. The manufacturer's profit and the whole supply chain profit remain at the benchmark level. The manufacturer's profit though, is independent of $\gamma$. That is, for any $\gamma$, the profits do not change.

Overall, SC profit is higher with lower $w$ than the benchmark $\bar{w}$.

\section{DR analysis}

Case 1. With all redeemers.

The optimization problem for the retailer is as follows:

$$
\max _{P} \Pi_{R}(P)=(P-w)(a-b P+d R) .
$$

The corresponding optimized price from FOC is given by following expression:

$$
P^{*}=\frac{1}{2}(a+w+d R) .
$$

With exogenous $w$, manufacturer's optimization problem is as per following expression:

$$
\begin{array}{cl}
\max _{R} & \Pi_{M}(R)=(w-c-R)(a-b P+d R) \\
\text { s.t. } & 0 \leq R \leq w-c . \\
& R^{*}= \begin{cases}\frac{1}{2}(w-c)-\frac{1}{2 d}(a-w) & \text { if } d>\frac{a-w}{w-c} . \\
0 & \text { o.w }\end{cases}
\end{array}
$$

For arbitrary $w$, we implicate two important insights:

(1) When $w$ is above benchmark optimal level, the manufacturer is better off with DR and generally creates win-win provided $d$ satisfies the threshold level.

(2) When $w$ is at the benchmark optimal, $R^{*}$ is essentially zero and the equilibrium solution is same as benchmark solution.

Case 2. With heterogeneous customers.

The optimization scenario for the retailer is given as follows:

$$
\max _{P} \Pi_{R}(P)=\alpha_{1}(P-w)(a-b P)+\alpha_{2}(P-w)(a-b P+d R)+\alpha_{3}(P-w)(a-b P+d R) .
$$

By first order condition, the price is given as follows:

$$
P^{*}=\frac{a}{2 b}+\frac{w}{2}+\frac{d R\left(\alpha_{2}+\alpha_{3}\right)}{2 b}
$$

The manufacturer maximizes $R$ for a given $w$ :

$$
\begin{array}{ll}
\max _{R} & \Pi_{M}(P)=\alpha_{1}(w-c)(a-b P)+\alpha_{2}(w-c)(a-b P+d R)+\alpha_{3}(w-c-R)(a-b P+d R) \\
\text { s.t. } & 0 \leq R \leq w-c .
\end{array}
$$

And optimal rebate is given by following expression:

$$
\begin{aligned}
R^{*} & =\frac{\frac{\left(\alpha_{2}+\alpha_{3}\right) d}{2}(w-c)-\frac{\alpha_{3}}{2}(a-w b)}{2 \alpha_{3} d-\alpha_{3} d\left(\alpha_{2}+\alpha_{3}\right)} \\
& =\frac{1}{2\left(1+\alpha_{1}\right)}\left[\frac{\alpha_{2}+\alpha_{3}}{\alpha_{3}}(w-c)-\frac{1}{d}(a-b w)\right]
\end{aligned}
$$

assuming $\alpha_{1}+\alpha_{2}+\alpha_{3}=1$. This is more realistic scenario and a profitable option for the manufacturer. The result is in line with Aydin and Porteus [4] who claim that DR is a profitable option for the manufacturer under customer heterogeneity. 


\subsection{Special case: $R R$ and $D R$ comparison}

(1) For all redeemers case, there is no common $R_{c}$ point that exists between RR and DR for $\gamma>d$ or $\gamma<d$. For $\gamma=d$ the manufacturer's profit as well as the whole SC profit is essentially the same for both promotional strategies.

(2) For heterogeneous customers, if $\mathrm{DR}>0$ we show that there always exists an indifferent point that points out the better rebate type for a given rebate amount.

The indifferent rebate value can be found by substituting optimal respective $P$ for $\mathrm{RR}$ and $\mathrm{DR}$ in the following expression:

$$
\alpha_{1}(w-c)(a-b P)+\left(\alpha_{2}+\alpha_{3}\right)(w-c)(a-b P+d R)-\alpha_{3} R(a-b P+d R)=(w-c-R)(a-b P+\gamma R) .
$$

Which simplifies to

$$
\begin{aligned}
& \beta_{2}=0 \\
& \beta_{1}=\frac{1}{2}(a-w)-\frac{1}{2}(w-c)+\frac{\left(\alpha_{2}+\alpha_{3}\right)(w-c) d}{2}-\frac{\alpha_{3}}{2}(a-w) \\
& \beta_{0}=\frac{1}{2}-\alpha_{3} d+\frac{\alpha_{3}\left(\alpha_{2}+\alpha_{3}\right) d}{2} .
\end{aligned}
$$

And by using quadratic formula for positive root we can show that

$$
\mathrm{RR} \leq R_{c} \leq \mathrm{DR}
$$

such that

$$
\Pi_{M_{\mathrm{RR}}} \leq \Pi_{M} \leq \Pi_{M_{\mathrm{DR}}}
$$

\section{Remarks}

For comparative analysis, we use $\alpha_{1}=0.2, \alpha_{2}=0.2$ and $\alpha_{3}=0.6$ with $\bar{w}=55$. Figure 2 is straightforward and shows that numerically indifferent point is 5 which is the same as analytical solution. Interestingly, such $R_{c}$ does not depend upon $\gamma$ as retailer is at liberty to adjust $P$. So whenever $\alpha_{2}>0$, threshold strategy exists for manufacturer.

\section{Observability improves overall profits in supply chain}

When the manufacturer controls price and induces the retailer to offer effective price as $P-\gamma R$, it improves manufacturer's profit. Customers see effective price to be reduced by the factor $\gamma R$. The implications are essentially the same as scenario 1 . So, observability of retail price allows the manufacturer and the whole SC chain better profits. In real world practices, manufacturers do publish manufacturer's suggested retail price $(M S R P)$, so that retailers cannot change price significantly.

\section{SuRVEy OF INDUSTRIAL PRACTICES}

In this section, we provide some important industrial practices related to the two scenarios which we discussed analytically. These practices are strong evidence of the applicability of the proposed models. First, we provide the industrial practices related to scenario 1 in Table 4.

Second, we provide the industrial evidence pertaining to scenario 2 in Table 5 .

These industrial practices provide concrete evidence for the need to determine the efficacy of retailer rebates and delayed rebates. Our analytical models depict the decision rules that help manufacturers to analyze both types of rebates under different market conditions. 


\section{DR with heterogeneity Vs. RR}

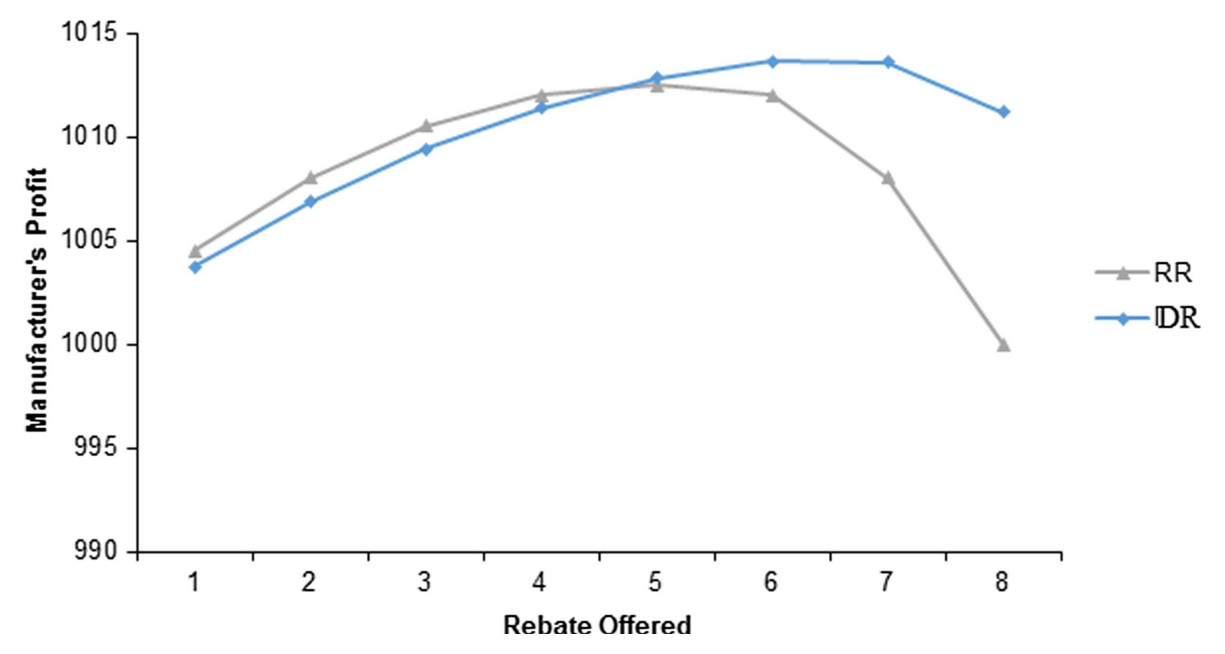

FiguRE 2. Indifferent level between RR and DR (heterogeneous) with $w=60$.

TABLE 4. Industrial examples for proposed models in scenario 1.

\begin{tabular}{|c|c|}
\hline $\begin{array}{l}\text { Proposed } \\
\text { model setting } \\
\text { in scenario } 1\end{array}$ & Industrial evidence \\
\hline $\begin{array}{l}\text { Long term } \\
\text { fixed } w \text { and } P\end{array}$ & $\begin{array}{l}\text { In automotive industry, manufacturers extensively use promotions and rebates, but very rarely } \\
\text { increase price. In fact, cooperative pricing has decreased the chances of changing wholesale price } \\
\text { drastically (J.D. Power and Associates). The exception was Chrysler's PT Cruise whose price } \\
\text { was raised because initially the manufacturer priced the vehicle too low [5]. Moreover, some } \\
\text { automotive dealers negotiate with customers and make use of rebate incentives as well. In such } \\
\text { a case they pass the rebate incentive to some customers to make the deal more attractive. So, in } \\
\text { automotive industry retailers rarely change the listed price and manufacturers hold the wholesale } \\
\text { price constant. This practice is an important evidence for our proposed strategy with long term } \\
\text { fixed wholesale price and retail price }\end{array}$ \\
\hline $\begin{array}{l}\text { Special case: } \\
\text { Comparison } \\
\text { of RR and } \\
\text { DR with } \\
\text { heterogeneity }\end{array}$ & $\begin{array}{l}\text { American auto manufacturers often use delayed rebates, whereas Japanese auto manufacturers } \\
\text { have more inclination towards offering incentives to their dealers [19]. Mazda and Toyota are } \\
\text { extensively exercising dealer incentive [36]. As such in automotive industry such different rebate } \\
\text { preferences invoke an interesting scenario of comparing the efficacy of these rebates for a given } \\
\text { rebate amount }\end{array}$ \\
\hline
\end{tabular}

\section{CONCLusion}

It is difficult to clearly demonstrate efficacy of different types of rebates to the manufacturer because of different need and adaptability in different industries. We analyze two scenarios which represent decision flexibility for the manufacturer and the retailer. We draw implications when both manufacturer and retailer do not change the advertised wholesale price and retail price respectively. We also discuss insights in a semi-rigid environment where manufacturer does not optimize wholesale price in response to optimized retail price but optimizes rebate. For analytical modeling, we used explicit customer heterogeneity for delayed rebates. They are characterized as rebate independent, fully rebate dependent and partially rebate dependent customers who 
TABLE 5. Industrial examples for proposed models in scenario 2.

\begin{tabular}{|c|c|}
\hline $\begin{array}{l}\text { Proposed } \\
\text { model setting } \\
\text { in scenario } 2\end{array}$ & Industrial evidence \\
\hline $\begin{array}{l}\text { Fixed } w \text { and } \\
\text { flexible } P\end{array}$ & $\begin{array}{l}\text { In home appliances and apparels industries, retailers may be allowed to adjust the retail price } \\
\text { in response to rebate while manufacturers hold the wholesale price constant [23]. Similar type } \\
\text { of practice was observed in fast moving goods manufacturers like paper and towel industries } \\
{[19]}\end{array}$ \\
\hline $\begin{array}{l}\text { Special case: } \\
\text { Comparison } \\
\text { of RR and } \\
\text { DR with } \\
\text { heterogeneity }\end{array}$ & $\begin{array}{l}\text { Kohl's black Friday ad for } 19 \text { th November } 2018 \text { to } 23 \text { rd November } 2018 \text { had } 501 \text { products with } \\
\text { instant coupons and } 135 \text { products with consumer rebates [27]. They also point out that slippage } \\
\text { which refers to proportion of rebates never redeemed after purchase could be as high as } 40 \% \text {. } \\
\text { These practices highlight the importance of instant rebates as a whole and delayed rebates } \\
\text { importance particularly for manufacturers. So, the optimal strategies for both rebates under } \\
\text { different market conditions are important from manufacturer's perspective }\end{array}$ \\
\hline $\begin{array}{l}\text { When all } \\
\text { customers } \\
\text { redeem DR }\end{array}$ & $\begin{array}{l}\text { The manufacturer designs rebate attractiveness such that all customers find it easy to redeem or } \\
\text { minimum effort is required to redeem it. Kingston technology (ww. kingston.com/en/rebates) } \\
\text { and ASUS (www.asus.com/us/site/promotion_center) provide extensive delayed rebates and } \\
\text { make the redemption process easy for their customers. Manufacturers of frequently purchased } \\
\text { consumer products sometimes offer rebates that are redeemed with the purchase and thus, } \\
\text { redemption is } 100 \% \text {. These industrial practices further strengthen our analytical models for } \\
\text { delayed rebates which are designed like coupons such that the redemption hassle is completely } \\
\text { eliminated. Still, manufacturers like ASUS and Kingston prefer delayed rebates with } 100 \% \\
\text { redemption over instant coupons because it provides them direct access to end customers }\end{array}$ \\
\hline
\end{tabular}

self-select segment based on rebate sensitivity and rebate value. Additionally, we devise a comparison between $\mathrm{RR}$ and DR for all three scenarios. This is a special case which allows manufacturer to select rebate type on the basis of fixed rebate amount. We demonstrate that a threshold level exists in rigid and semi-rigid scenarios. Such threshold allows manufacturer to select better rebate type for a given rebate value.

This study provides useful insights for manufacturers about different rebate strategies. Future avenue of research could be the micro modeling of the consumer's behavior based on some utility function. Another area of research could be to model a situation when manufacturers offer rebates to some specific customer segment while, customers perceive different price sensitivities. Under stochastic setting one more interesting research extension could be rebate offered only on actual sold items where moral hazard could occur; it would be interesting designing contract for a manufacturer who could reduce retailer's incentive to misreport actual sales.

\section{ApPEndix A.}

Proof for Proposition 4.4.

$$
\Pi_{R}=(P-w+R-\gamma R)(a-b P+\gamma R) .
$$

For the manufacturer, the objective is to maximize:

$$
\Pi_{M}=(w-c-R)(a-b P+\gamma R) .
$$

Similarly, the results for DR without customer heterogeneity $\left(\alpha_{1}=1\right)$ are as follows:

$$
\Pi_{R}=(P-w)(a-b P+d R) .
$$


For the manufacturer, the objective is to maximize:

$$
\Pi_{M}=(w-c-R)(a-b P+d R) .
$$

The result immediately follows when $\gamma=d$.

Proof of Lemma 4.3. Without loss of generality, we modify the manufacturer's optimization problem with heterogeneity given by equation (4.1) to all redeemers problem by assuming $\alpha_{1}+\alpha_{2}+\alpha_{3}=1$.

Thus, we have the following transformed optimization problem according to Kuhn-Tucker condition.

$$
\begin{aligned}
& \Pi_{R}=(w-c-R)(a-b P+d R)+\lambda R \\
& \text { s.t. } \\
& w-c-R \geq 0 \\
& R \geq 0 .
\end{aligned}
$$

We have to satisfy the constraint $w-c-R \geq 0$. This is because at the point where this constraint is equal to zero, the manufacturer has zero profit. Any feasible solution other than this point is better off. Therefore, we only need to consider $R \geq$ in Lagrange function.

$$
\begin{aligned}
L_{M} & =(w-c-R)(a-b P+d R)+\lambda R \\
\frac{\partial L_{M}}{\partial R} & =-(a-b P+d R)+(w-c-R) d+\lambda .
\end{aligned}
$$

We need to discuss two cases; $\lambda=0$ and $\lambda>0$.

(1) For first case $\lambda=0$ we have

$$
R=\frac{1}{2}\left[(w-c)-\frac{a-b P}{d}\right] .
$$

For $\lambda>0$, we have $R=0$ by complementary slackness.

On the similar lines, we can prove rebate expression for heterogeneous customers. Note that the manufacturer's objective function is a concave function and $0 \leq R \leq w-c$. Therefore, if $R \geq 0$, we have $d \geq \frac{\alpha_{3}(a-b P)}{\left(\alpha_{2}+\alpha_{3}\right)(w-c)}$ and the optimal rebate expression is given by following expression:

$$
R^{*}=\min \left\{w-c, \frac{1}{2}\left[\frac{\alpha_{2}+\alpha_{3}}{\alpha_{3}}(w-c)-\frac{(a-b P)}{d}\right]\right\}
$$

otherwise $R^{*}=0$.

This completes the proof.

Proof for Theorem 4.5. For $\gamma \neq d$ and by marginal analysis $(w-c-R)(a-b P+\gamma R)=(w-c-R)(a-b P+d R)$

$$
\begin{aligned}
\beta_{0} & =-\gamma+d \\
\beta_{1} & =-d(w-c)+\gamma(w-c) \\
\beta_{2} & =0 \\
R_{c} & =\frac{-\beta_{1} \pm \sqrt{\beta_{1}^{2}-4 \beta_{0} \beta_{2}}}{2 \beta_{0}} .
\end{aligned}
$$

Here $R_{c}$ represents the crossing value of rebate and satisfies $\mathrm{RR} \leq R_{c} \leq \mathrm{DR}$. So if such $R_{c}$ exists, it shows the coexistence of both the rebates with same profit for the manufacturer. Above this value DR supersedes RR and RR outperforms DR below such $R_{c}$.

From the two roots we can find the equilibrium point that maximizes the function.

Acknowledgements. The authors would like to thank anonymous referees and the area editor for the constructive suggestions that has improved both the quality and clarity of the paper. 


\section{REFERENCES}

[1] F.J. Arcelus, S. Kumar and G. Srimivasan, Retailer's response to alternate manufacturer's incentives under a single-period, price dependent, stochastic-demand framework. Decis. Sci. 36 (2005) 599-626.

[2] F.J. Arcelus, S. Kumar and G. Srimivasan, Pricing, rebate, advertising and ordering policies of a retailer facing price-dependent stochastic demand in newsvendor framework under different risk preferences. Int. Trans. Oper. Res. 13 (2006) $209-227$.

[3] R.W. Ault, T.T. Beard, N.D. Laband and R.P. Saba, Rebates, inventories, and intertemporal price discrimination. Econ. Inquiry 38 (2000) 570-578.

[4] G. Aydin and E.L. Porteus, Manufacturer-to-retailer versus manufacturer-to-consumer rebates in a supply chain, edited by N. Agrawal and S. Smith. In: Retail Supply Chain Management. Springer, New York (2009) 237-270.

[5] S. Biller, L.M. Chan, D.S. Levi and J. Swan, Dynamic pricing and the direct-to-customer model in the automotice industry. Electron. Commer. Res. 5 (2005) 309-334.

[6] R.C. Blattberg and S.A. Neslin, Sales Promotion: Concepts, Methods, and Strategies. Prentice-Hall Inc., Englewood Cliffs, NJ (1990).

[7] R.C. Blattberg and K.J. Wisniewski, Price-induced patterns of competition. Mark. Sci. 8 (1989) $291-309$.

[8] R.C. Blattberg, G. Eppen and J. Lieberman, A theoretical and empirical evaluation of price deals for consumer nondurables. J. Mark. 45 (1981) 116-129.

[9] N. Bruce, P. Desai and R. Staelin, The better they are, the more they give: trade promotions of consumer durables. J. Mark. Res. 42 (2005) 54-66.

[10] N. Bruce, P. Desai and R. Staelin, Enabling the willing: consumer rebates for durable good. Mark. Sci. 25 (2006) $350-366$.

[11] M. Busse, P. Desai and R. Staelin, \$1000 Cash back: the pass through of auto manufacturer promotions. Am. Econ. Rev. 96 (2006) 1253-1270.

[12] R.D. Buzzell, J.A. Quelch and W.J. Salmon, The costly bargain of trade promotion. Harv. Bus. Rev. 68 (1990) $141-149$.

[13] G.P. Cachon, Supply chain coordination with contracts, edited by A.G. deKok and S.C. Graves. In: Vol. 11 of Handbooks in Operations Research and Management Science. Supply Chain Management, Design, Coordination and Operation. Elsevier, Amsterdam (2003) 229-340.

[14] Y. Chen, S. Moorthy and Z.J. Zhang, Price discrimination after the purchase? A note on rebates as state-dependent discounts. Manage. Sci. 51 (2005) 1131-1140.

[15] X. Chen, C.-L. Li, B.D. Rhee and D. Simchi-Levi, The impact of manufacturer rebates on supply chain profits. Naval Res. Logist. 54 (2007) 667-680.

[16] S. Cho, K.F. McCardle and C.S. Tang, Optimal pricing and rebate strategies in a two-level supply chain. Prod. Oper. Manage. 18 (2009) 424-446.

[17] C.J. Corbett and U.S. Karmarkar, Competition and structure in serial supply chains with deterministic demand. Manage. Sci. 47 (2001) 966-978.

[18] R.J. Dalton Jr., Many consumers never cash in rebates. Newsday (January, 2005).

[19] O. Demirag, O. Baysar, P. Keskinocak and J. Swann, The effects of customer rebates and retailer incentives on a manufacturer's profits and sales. Naval Res. Logist. 57 (2010) 88-108.

[20] E. Gerstner and J.D. Hess, A theory of channel price promotions. Am. Econ. Rev. 81 (1991) 872-886.

[21] E. Gerstner and J.D. Hess, Pull promotions and channel coordination. Mark. Sci. 14 (1995) 43-60.

$[22]$ B. Grow, The great rebate tunaround. Business Week (November 23, 2005).

[23] M.H. Guiomar, S.P. Sigue and G. Zaccour, The dilemma of pull and push-price promotions. J. Retail. 86 (2010) 51-68.

[24] A.P. Jeuland and S.M. Shugan, Managing channel profits. Mark. Sci. 2 (1983) 239-272.

[25] M. Jolson, J. Weiner and R. Rosecky, Correlates of rebate proneness. J. Advert. Res. 27 (1987) 33-43.

[26] M. Khouja, S. Robbins and H.K. Rajagopalan, Optimal pricing and delayed incentives in heterogeneous consumer market. J. Revenue Pricing Manage. 7 (2008) 85-105.

[27] M. Khouja, C. Subramaniam and V. Vasudev, A comparative analysis of marketing promotions and implications for data analytics. Int. J. Res. Mark. 37 (2020) 151-174.

[28] R. Lal, Manufacturer trade deals and retail price promotions. J. Mark. 27 (1990) 428-444.

[29] W. Mouland, Rebates rule. Mark. Mag. 109 (2004) 1196-4650.

[30] C. Narasimhan, Competitive promotional strategies. J. Bus. 61 (1988) 427-449.

[31] S.A. Neslin, Sales Promotion. Marketing Science Institute (MSI), Cambridge, MA (2002).

[32] S. Saha, Supply chain coordination through rebate induced contracts. Transp. Res. Part E: Logist. Transp. Rev. 50 (2013) 120-137.

[33] T.G. Silk, Why do We Buy but Fail to Redeem? Department of Marketing, University of South Carolina, Columbia, SC (2005).

[34] D. Soman, The illusion of delayed incentives: evaluating future effort-money transactions. J. Mark. Res. 35 (1998) $427-437$.

[35] S. Srinivasan, K. Pawels, D.M. Hanssens and M. Dekimpe, Do promotions benefit manufacturer, retailers or both? Manage. Sci. 50 (2004) 617-629.

[36] T.A. Taylor, Supply chain coordination under channel rebates with sales effort effects. Manage. Sci. 48 (2002) $992-1007$.

[37] L.H. Teunter, Analysis of sales promotion effects on household purchasing behavior, ERIM Ph.D. research series in management. Erasmus University, Rotterdam (2002).

[38] Y.C. Tsao, H.L. Fan, L.W. Liao, T.L. Vu and P.L. Lee, Two-level promotion and ordering policy in a supply chain. RAIRO: OR 55 (2021) S119-S145.

[39] H.R. Varian, A model of sales. Am. Econ. Rev. 70 (1980) 651-660. 